\title{
Proceedings of peer-reviewed and selected articles from Turgut Ozal University Faculty of Medicine 7th International Student Congress
}

\footnotetext{
Abstract

Turgut Ozal University Scientific Research Committee (TOBAT) was established at Turgut Ozal University Faculty of Medicine in 2009 to encourage young medical students and scientists to carry out novel scientific research in addition to their medical education. Every year a committee (Chair, Student Member and Scientific and Social Committees, and Advisory Chair) is set up by the volunteer students and their advisors to organize the congress, with the help of the previous year's Committee.
} 
Turgut Ozal University Scientific Research Committee (TOBAT) was established at Turgut Ozal University Faculty of Medicine in 2009 to encourage young medical students and scientists to carry out novel scientific research in addition to their medical education. Every year a committee (Chair, Student Member and Scientific and Social Committees, and Advisory Chair) is set up by the volunteer students and their advisors to organize the congress, with the help of the previous year's Committee.

The aim of TOBAT is threefold: to establish a platform of informing the latest advancements in science; to present this work to colleagues; and, to meet and interact with their peers within the international medical and scientific community. Each year, our the Committee organizes the International Medical Student Congress (IMSC): a meeting of Turkey's most highly-qualified medical students, with the highest number of presenters and attendants. In April 2016, over 1200 medical students and experts attended IMSC to present, learn and discuss new research in medicine.

Because of the international nature of this congress, experts, scientists and attendants from other countries enrich the content and atmosphere of the congress: excellent research was presented and the global biomedical research network was strengthened.

IMSC was covered by the media, both print and television, and had a positive impact on public opinion. The conference organization, design and coordination and the configuration of the scientific program were all completed by Turgut Ozal University's medical students, with the assistance of their supervisors, which was a success in itself.

Research and scientific work performed by students composed the main portion of the IMSC. The 2016 congress included 146 oral and 34 posters presentations. The topics covered often show the promise of playing an important role in the future of medical research. Last years' Topics included research in synthetic biology, hearth rate variability, cancer research and stress.

For the past two years, we have included a very important opportunity for the congress attendees: the publication of selected studies in a supplement of the Journal of Clinical and Investigative Medicine. We believe that this opportunity has encouraged the young scientists to improve their research skills, to carry out better and more novel studies and to collaborate more effectively with each other. The selection was difficult because of the high quality of the scientific research. In this supplementary, there are many well-documented studies on a wide range of topics. By seeing the quality and breadth of these topics, the contributions and potential impact of our congress to the scientific community can be better understood.

We wish to express our sincere appreciation to the editors of the Journal of Clinical and Investigative Medicine for their editing and their support in publishing this supplementary material. We would also like to take this opportunity to thank the Rector of Turgut Ozal University, the Dean and Vice Dean of the Faculty of Medicine, our instructors, mentors, seniors, advisors and technical staff for their kind advice and assistance in organizing with this huge undertaking.

Kind regards,

Furkan Sacit Ceylan

Student Chair

On Behalf of the Turgut Ozal University

Scientific Research Committee (TOBAT)

\section{5/2016 Turgut Ozal University Scientific Research Committee:}

Student Chair:

Furkan Sacit Ceylan

Student Scientific Committee:

Burcu Nur Basdan

Student Social Committee:

Asli Avci and

Osman Nuri Is

Advisory Chair:

Senol Dane, MD,

Vice Dean

Faculty of Medicine,

Turgut Ozal University 